\title{
Diffusion enhancement of low-temperature pack aluminizing on austenitic stainless steel AISI 304 by deep rolling process
}

\author{
W. Yutanorm, P. Juijerm* \\ Department of Materials Engineering - Metals Research Group, Faculty of Engineering, Kasetsart University, \\ 50 Ngamwongwan Rd., Ladyao, Jatujak, Bangkok 10900, Thailand
}

Received 18 June 2015, received in revised form 15 November 2015, accepted 19 November 2015

\begin{abstract}
The deep rolling process is a mechanical surface treatment which plastically deforms only the surface and near-surface regions. The deep rolled AISI 304 austenitic stainless steel has been investigated to illustrate the near-surface plastic deformation effect on the aluminium diffusion rate in the low-temperature pack aluminizing process. Near-surface properties such as residual stresses and full width at half maximum (FWHM) values were measured using the $\mathrm{X}$-ray diffractometer (XRD). The deep rolled, and non-deep rolled specimens were aluminized using powder pack method at the relatively low temperature of $550{ }^{\circ} \mathrm{C}$ for about $2-8 \mathrm{~h}$. A scanning electron microscope (SEM) with energy dispersive X-ray spectrometer (EDS) and XRD were used to characterize the surface layers. It was found that the deep rolled condition shows the higher diffusion coefficient as compared to the non-deep rolled condition. Finally, it can be mentioned that the deep rolling process can enhance the diffusion rate of the pack aluminizing treatment at the temperature of $550{ }^{\circ} \mathrm{C}$.
\end{abstract}

K e y w or d s: stainless steel, aluminizing, deep rolling, diffusion, mechanical surface treatment

\section{Introduction}

Recently, there are many modern and complicated applications involving a service at high temperature and corrosion in petroleum, chemical industries or a steam turbine blade [1]. Therefore, many conventional austenitic stainless steels were frequently selected due to their good high-temperature creep strength, oxidation and corrosion resistance at a reasonable cost. However, at the temperature higher than about 600 $650^{\circ} \mathrm{C}$, the protectiveness of a passive film of the austenitic stainless steels will be declined and finally causes failure [2, 3]. Accordingly, various surface treatments are mentioned to improve the oxidation and corrosion resistance. An aluminizing process is a wellknown thermochemical surface treatment to add as well as diffuse aluminium atoms into the surface of stainless steels or nickel base alloys, whereas a superior high-temperature oxidation resistance is reported in [4-6]. The aluminizing process is usually operating at a relatively high temperature of $800-1000^{\circ} \mathrm{C}$ with pro- longed soaking time taking into account the diffusion concept. To decrease the grain growth, carbide precipitation and distortion, there are many investigations relating a low-temperature aluminizing process, which is operating at a temperature below $700^{\circ} \mathrm{C}$ [7-9]. However, the diffusion rate of aluminium atoms decreases with decreasing temperature, although many concerns are relieved by a low-temperature aluminizing process. Consequently, it cannot be refused that the aluminizing time will be extended for the low-temperature aluminizing process. Bulk plastic deformation is a way to enhance the diffusion rate as reported in [10]. However, the aluminizing process emphasizes only at the surface and in near-surface regions. Thus, plastic deformation only at the surface and in near-surface regions should be considered to improve the diffusion rate for the thermochemical surface treatments. The deep rolling process is the mechanical surface treatment, which plastically deforms the surface and nearsurface regions of metallic materials $[11,12]$. Therefore, for these mentioned reasons, the effects of the

\footnotetext{
${ }^{*}$ Corresponding author: tel.: +6681 807 6894; fax: +662 955 1811; e-mail addresses: fengppj@ku.ac.th, juijerm@gmail.com
} 


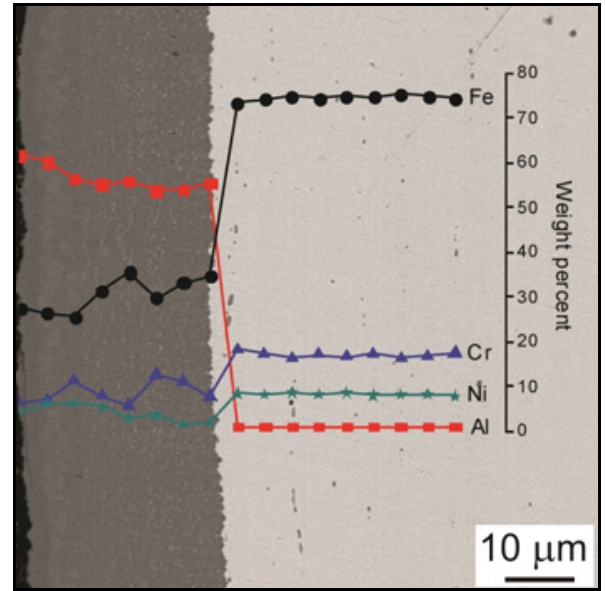

Fig. 1. Aluminized layer with the SEM-EDS in backscattered electron mode after aluminizing process at a temperature of $550{ }^{\circ} \mathrm{C}$ for about $6 \mathrm{~h}$.

deep rolling process on the diffusion rate of the pack aluminizing treatment on the austenitic stainless steel AISI 304 at the relatively low temperatures are of particular interest and will be addressed in this research. Deep rolled and non-deep rolled specimens are aluminized at a temperature of $550{ }^{\circ} \mathrm{C}$ for about $2-8 \mathrm{~h}$. Finally, the diffusion coefficient of the deep rolled and non-deep rolled conditions can be calculated and compared.

\section{Experimental procedures}

The stainless steel AISI 304 bars whose composition is as: $0.045 \% \mathrm{C}, 0.43 \% \mathrm{Si}, 1.60 \% \mathrm{Mn}, 0.025 \% \mathrm{~S}$, $0.031 \% \mathrm{P}, 8.65 \% \mathrm{Ni}, 18.26 \% \mathrm{Cr}$ and Fe balance (all values in wt.\%) was used in this research. The deep rolling process was performed using a single roller with a diameter of $40 \mathrm{~mm}$, with a rolling force of about $0.75 \mathrm{kN}$. Afterwards, the specimens were prepared in a disc shape with a diameter of $12 \mathrm{~mm}$ and a thickness of $5 \mathrm{~mm}$. For the non-deep rolled specimens, their surfaces were ground using $\mathrm{SiC}$ abrasive paper up to 600 grit and then cleaned in ultrasonic cleaner before the aluminizing process. The aluminizing powder contained $25 \%$ master alloy of aluminium (with containing $97 \%$ aluminium) as aluminium ( $\mathrm{Al}$ ) source, $65 \%$ alumina as inert filler and $10 \% \mathrm{NH}_{4} \mathrm{Cl}$ as halide activator (all values in wt.\%). The non-deep rolled and deep rolled specimens were packed and buried in a steel container with aluminizing powder and then sealed with a lid and cement. The aluminizing process was performed using an electrical furnace with argon atmosphere at the temperature of $550^{\circ} \mathrm{C}$ for 2 $8 \mathrm{~h}$ and followed by cooling in air. Microstructures, thicknesses and kind of the formed layers were characterized using the conventional SEM with EDS and
$\mathrm{XRD}$ with $\mathrm{Cu} \mathrm{K}_{\beta}$ radiation source. For the deep rolled specimen, the hardness depth profile was characterized using a Vicker microhardness tester with load of $100 \mathrm{~g}$ and time of $15 \mathrm{~s}$. Residual stress and FWHM-value depth profiles were determined by successive electrolytic material removal and the classical $\sin ^{2} \psi$ -method using $\mathrm{Cr} \mathrm{K}_{\beta}$ radiation at the 311-planes and $1 / 2 s_{2}=5.985 \times 10^{-6} \mathrm{MPa}^{-1}$ as an elastic constant. Near-surface work hardening was characterized by the full width at half maximum (FWHM) values of the X-ray interference lines. All residual stresses and FWHM values were measured in longitudinal direction of the specimens. No stress correction was carried out after electrolytic material removal of surface layers.

\section{Results and discussion}

\subsection{Non-deep rolled austenitic stainless steel AISI 304}

Firstly, to verify the low-temperature aluminizing process, the aluminizing process was performed on the non-deep rolled austenitic stainless steel AISI 304 at the temperature of $550{ }^{\circ} \mathrm{C}$ for about $6 \mathrm{~h}$. It was found that there was a formed layer with a thickness of about $25 \mu \mathrm{m}$ as shown in Fig. 1. The SEM-EDS was used to identify the elements of the formed layer. The results are embedded into the cross-sectional microstructure in Fig. 1. The aluminium content of about 55-60 wt.\% was detected along the formed layer. In the substrate of the austenitic stainless steel AISI 304, the aluminium content less than 1 wt.\% was observed. The iron content of about 25-35 wt.\% was also found in the formed layer. Therefore, the formed layer should be a Fe-Al intermetallic layer. XRD spectra were used to confirm the types of the phases as shown in Fig. 2. The $\mathrm{FeAl}_{3}$ and $\mathrm{Fe}_{2} \mathrm{Al}_{5}$ phases were observed after the aluminizing process at a temperature of $550^{\circ} \mathrm{C}$ for about $6 \mathrm{~h}$. Moreover, the aluminized layer is smooth and has more compact morphology because of high alloying elements in the investigated steel [13]. It is because the chromium and nickel atoms in the austenitic stainless steel AISI 304 retard the diffusion of aluminium atoms during the aluminizing process. This phenomenon is also observed in other thermochemical surface treatments such as the boronizing process on stainless steels as is reported in $[14,15]$. The Fe-Al intermetallic phases, $\mathrm{FeAl}_{3}$ and $\mathrm{Fe}_{2} \mathrm{Al}_{5}$, were detected clearly due to the powder pack contained high $\mathrm{Al}$ amount up to $25 \mathrm{wt} . \%$ [16-18]. Also, the aluminized layers increase with increasing aluminizing time taking into account diffusion theory [19-23]. The squared thickness of aluminized layer as a function of time can be explained in Eq. (1) as follows:

$$
d^{2}=K t,
$$




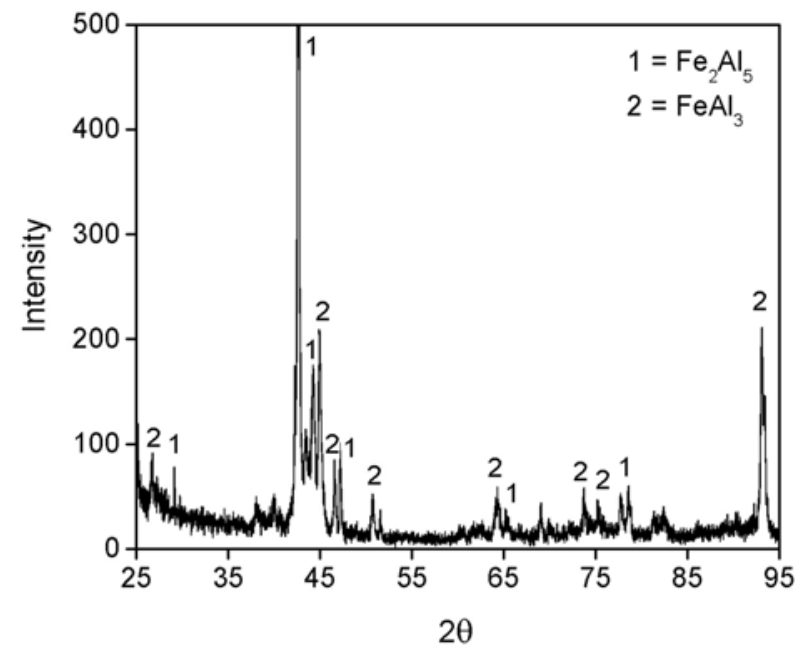

Fig. 2. XRD spectra of the aluminized layer after aluminizing process at a temperature of $550^{\circ} \mathrm{C}$ for about $6 \mathrm{~h}$.

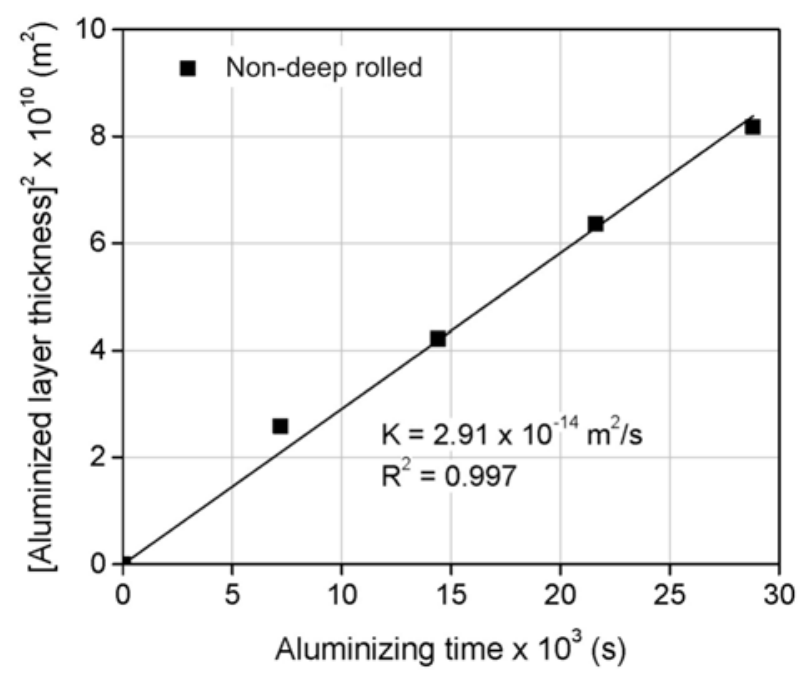

Fig. 3. Diagram of the square of the aluminized layer thickness values versus aluminizing time.

where $d$ is the thickness of aluminized layer $(\mathrm{m}), t$ is process time (s), $K$ is the growth rate constant depending on the aluminizing temperature and can be determined by a slope of a straight line in a diagram of $d^{2}$ as a function of aluminizing time at the given aluminizing temperature as shown in Fig. 3. The growth rate constant, $K$, of $2.91 \times 10^{-14} \mathrm{~m}^{2} \mathrm{~s}^{-1}$ is calculated for the aluminized non-deep rolled austenitic stainless steel AISI 304.

\subsection{Deep rolled austenitic stainless steel AISI 304}

The deep rolling process is a mechanical surface treatment which deforms the surface plastically and

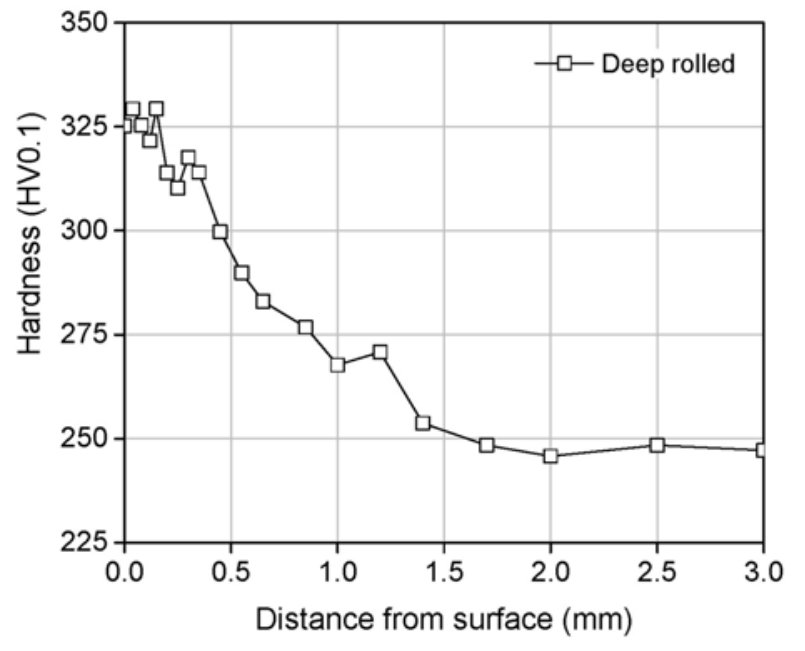

Fig. 4. Hardness depth profile of the deep rolled austenitic stainless steel AISI 304.

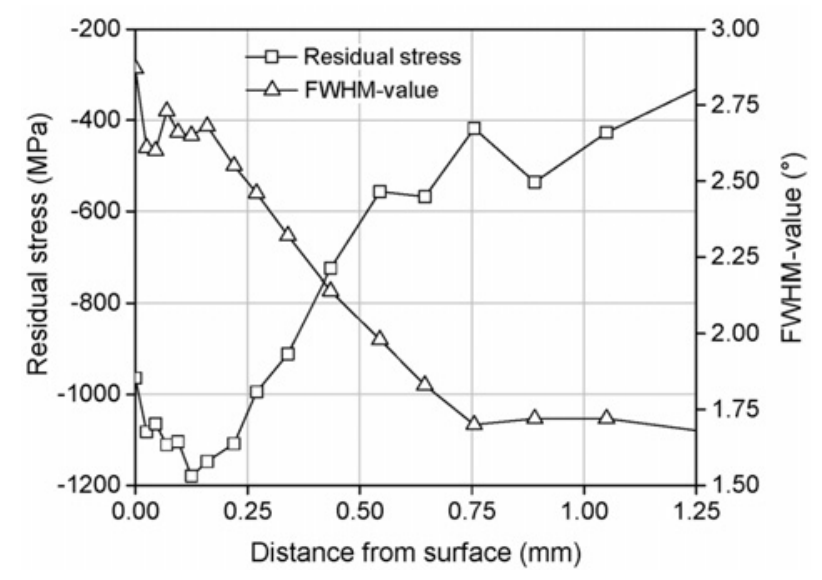

Fig. 5. Residual stress and FWHM depth profile of the deep rolled austenitic stainless steel AISI 304.

in near-surface of specimens. Therefore, after the deep rolling process, the surface and the near-surface region of the austenitic stainless steel are altered due to the localized plastic deformation at the surface and in near-surface regions. Consequently, hardness values increase from about $250 \mathrm{HV}$ of the substrate to about $325 \mathrm{HV}$ at the deep rolled surface as depicted in Fig. 4. The maximum compressive residual stress of $-1179.5 \mathrm{MPa}$ was measured at about $125 \mu \mathrm{m}$ beneath the surface. The compressive residual stresses decrease continuously into the substrate as shown in Fig. 5. The work hardened layer can be represented using the FWHM values of the X-ray interference lines. At the surface, the FWHM value of about $2.87^{\circ}$ was measured and then decreased continuously to about $1.62^{\circ}$ in the substrate (see in Fig. 5). The higher FWHM value could be used to refer indirectly to increased 
dislocation densities at the surface and near-surface regions after mechanical surface treatment [24, 25]. After aluminizing process at a temperature of $550{ }^{\circ} \mathrm{C}$ for about $6 \mathrm{~h}$, the aluminized layer with the thickness of $31 \mu \mathrm{m}$ was also observed. The aluminium contents at the surface and in near-surface regions of the deep rolled condition are comparable to the non-deep rolled condition as shown in Fig. 6. Moreover, the aluminized layer thicknesses of the deep rolled condition are higher than those of the non-deep rolled condition at the same aluminizing process parameters. The aluminized layers of the deep rolled condition increase also with increasing aluminizing time taking into account diffusion theory. The growth rate constant, $K$, of $4.58 \times 10^{-4} \mathrm{~m}^{2} \mathrm{~s}^{-1}$ is considered using a slope of the squared thickness of aluminized layer as the function of time in Fig. 7 depicting a comparison of the aluminized deep rolled and non-deep rolled austenitic stainless steel AISI 304. The effects of the deep rolling process on the diffusion rate of the aluminizing process are clearly seen. It is because the deep rolling process provides localized plastic deformation at the surface and in near-surface regions as a consequence of increased dislocation densities. Therefore, the volume diffusion process is enhanced by increased dislocation densities $[10,11,26]$ at the surface and in near-surface regions of the deep rolled condition during the aluminizing process at the temperature of $550^{\circ} \mathrm{C}$. Moreover, many researches show that the grain size at the severely deformed surface is smaller than that of the substrate as reported in [26-28]. Hence, an increase of numbers of grain boundaries at the surface and in near-surface regions of the deep rolled condition is another reason of a diffusion rate enhancement in the aluminizing process. Nevertheless, in general, residual stresses and work hardened layer generated by mechanical surface treatments will be annealed out at the high temperature named a thermal relaxation. The recovery is an important mechanism of thermal relaxation of residual stresses and FWHM values [24, 29-32]. It should be noted that the thermal relaxation behaviour depends strongly on a kind of metallic materials, dislocation densities, arrangement and annihilation. Therefore, it could be mentioned that the beneficial effects of the deep rolling process or other mechanical surface treatments on the diffusion rate should be deteriorated at a high operating temperature due to the thermal relaxation phenomenon. On the other hand, for the relatively low operating temperature of the thermochemical surface treatments, the beneficial effects of the mechanical surface treatments are observed as reported in $[10,11]$. At an aluminizing temperature of $550^{\circ} \mathrm{C}$, the thermal relaxation of the deep rolled austenitic stainless steel AISI 304 occurs certainly as reported in [32], but the degree of the thermal relaxation is still not much more pronounced. That means that the deep rolling process en-

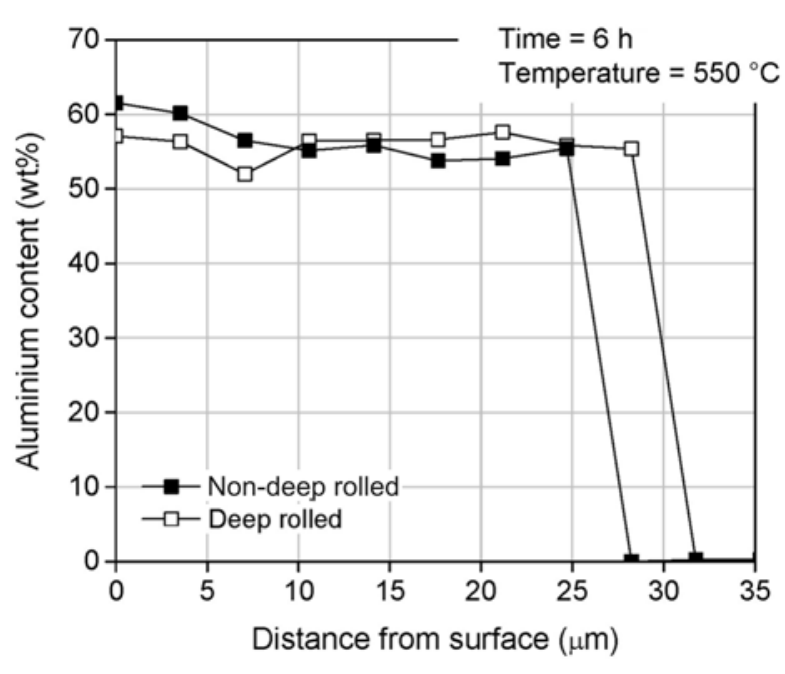

Fig. 6. Aluminium contents at the surface and in nearsurface regions of the deep rolled and non-deep rolled conditions.

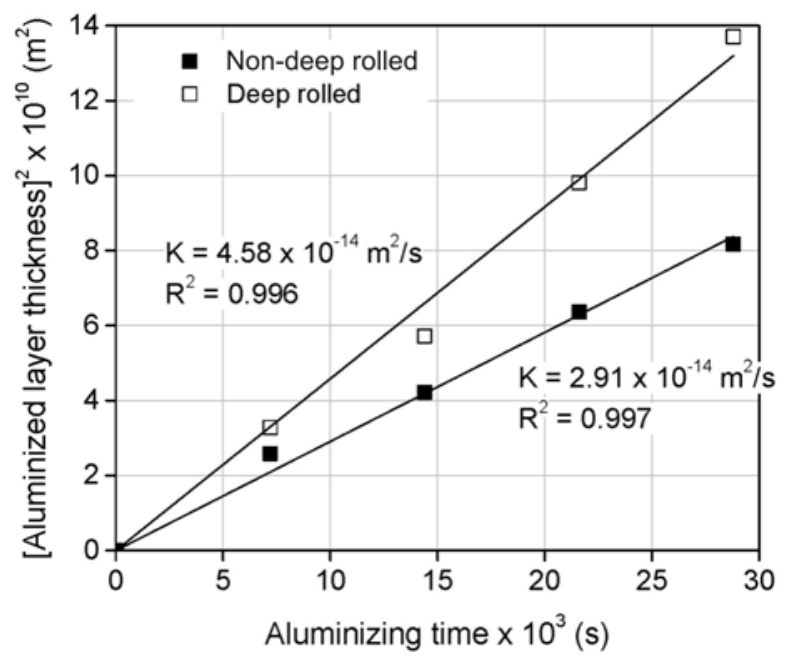

Fig. 7. Diagram of the square of the aluminized layer thickness values versus aluminizing time of the deep rolled and non-deep rolled conditions.

hances more or less for the diffusion rate of aluminium atoms in the aluminizing process at the temperature of $550^{\circ} \mathrm{C}$. This mentioned discussion can be obviously verified by the experimental results in Fig. 8 illustrating a greater aluminized layer thickness of the deep rolled condition as compared to the non-deep rolled condition after aluminizing process at a temperature of $550^{\circ} \mathrm{C}$ for about $8 \mathrm{~h}$.

\section{Conclusions}

The effects of the deep rolling process on the dif- 


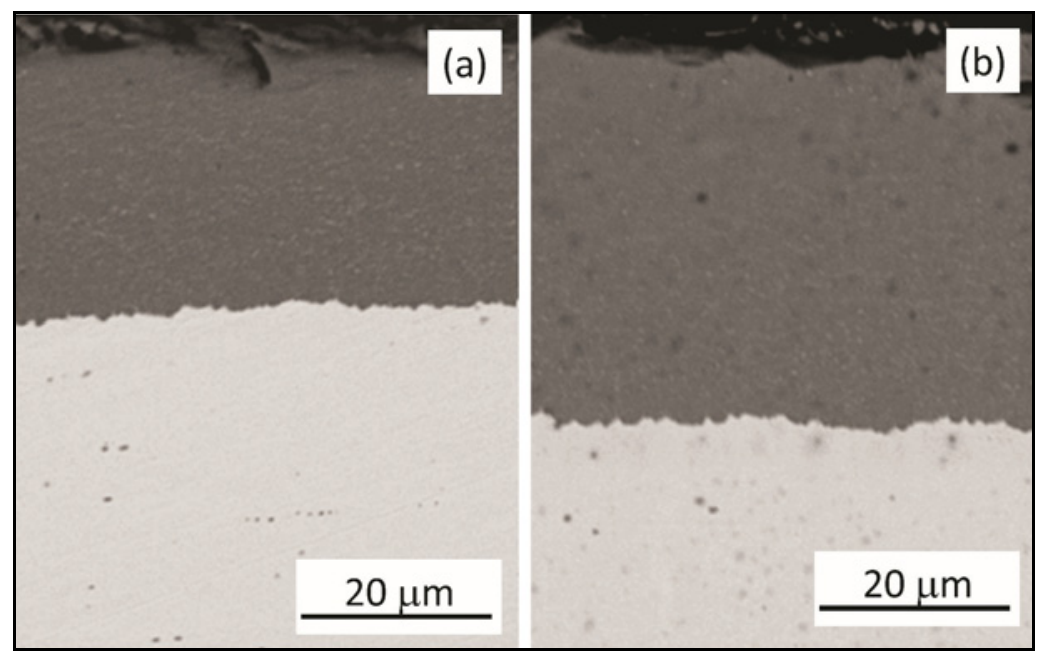

Fig. 8. Comparison of aluminized layers between (a) non-deep rolled and (b) deep rolled conditions after aluminizing process at the temperature of $550^{\circ} \mathrm{C}$ for about $8 \mathrm{~h}$.

fusion rate of aluminium atoms of the relatively low-temperature pack aluminizing treatment on austenitic stainless steel AISI 304 at the temperature of $550{ }^{\circ} \mathrm{C}$ are clarified and concluded.

1. The aluminized layers can be formed on the deep rolled, and non-deep rolled austenitic stainless steel AISI 304 using the aluminizing process at a temperature of $550{ }^{\circ} \mathrm{C}$. The intermetallic phases of $\mathrm{Fe}_{2} \mathrm{Al}_{5}$ and $\mathrm{FeAl}_{3}$ were observed after the aluminizing process.

2. The thicknesses of the aluminized layers on deep rolled and non-deep rolled austenitic stainless steel AISI 304 increase with increasing the aluminizing time taking into account the diffusion theory. The diffusion coefficients of $2.91 \times 10^{-14}$ and $4.58 \times 10^{-14} \mathrm{~m}^{2} \mathrm{~s}^{-1}$ can be calculated for the non-deep rolled and deep rolled conditions, respectively.

3 . The deep rolling process can enhance the diffusion rate of $\mathrm{Al}$ atoms during the aluminizing process at the given temperature of $550^{\circ} \mathrm{C}$ due to the increased dislocation densities, and the degree of the thermal relaxation is still not much more pronounced at this temperature for the austenitic stainless steel AISI 304.

\section{Acknowledgements}

Sincere thanks are expressed to the Faculty of Engineering, Kasetsart University, Thailand for financial support for W. Yutanorm. Thanks are due to the Department of Production Engineering, King Mongkut's University of Technology North Bangkok (KMUTNB) and the Residual Stress and Fatigue Excellent Center (ReFEC), Iron and Steel Institute of Thailand (ISIT), Thailand for support of some experiments.

\section{References}

[1] Jonas, O., Machemer, L.: In: Proceedings of the 37th Turbomachinery Symposium. Ed.: Childs, D. Houston, A\&M Uni. of Texas 2008, p. 211.

[2] Aguero, A., Muelas, R., Gutierrez, M., Van Vulpen, R., Osgerby, S., Banks, J. P.: Surf. Coat. Tech., 201, 2007, p. 6253. doi:10.1016/j.surfcoat.2006.11.033

[3] Sharafi, S., Farhang, M. R.: Surf. Coat. Tech., 200, 2006, p. 5048. doi:10.1016/i.surfcoat.2005.05.024

[4] Su, C. W., Lee, J. W., Wang, C. S., Chao, C. G., Liu, T. F.: Surf. Coat. Tech., 202, 2008, p. 1847. doi:10.1016/j.surfcoat.2007.08.011

[5] Tortorelli, P. F., Natesan, K.: Mat. Sci. Eng. A-Struct., 258, 1998, p. 115. doi:10.1016/S0921-5093(98)00924-1

[6] Zhang, Z. G., Peng, Y. P., Mao, Y. L., Pang, C. J., Lu, L. Y.: Corros. Sci., 55, 2012, p. 187. doi:10.1016/i.corsci.2011.10.029

[7] Wang, Y. Q., Zhang, Y., Wilson, D. A.: Surf. Coat. Tech., 204, 2010, p. 2737. doi:10.1016/j.surfcoat.2010.02.025

[8] Zhou, Z. H., Xie, F., Hu, J.: Surf. Coat. Tech., 203, 2008, p. 23. doi:10.1016/i.surfcoat.2008.07.021

[9] Si, X., Lu, B. N., Wang, Z. B.: J. Mater. Sci. Technol., 25, 2009, p. 433.

[10] Ferkel, H., Glatzer, M., Estrin, Y., Valiev, R. Z.: Scripta Mater., 46, 2002, p. 623. doi:10.1016/S1359-6462(02)00031-3

[11] Xiang, Z. D., Datta, P. K.: Acta Mater., 54, 2006, p. 4453. doi:10.1016/j.actamat.2006.05.032

[12] Guo, S., Wang, Z. B., Wang, L. M., Lu, K.: Surf. Coat. Tech., 258, 2014, p. 329. doi:10.1016/j.surfcoat.2014.09.005

[13] Hwang, S. H., Song, J. H., Kim, Y. S.: Mat. Sci. Eng. A-Struct., 390, 2005, p. 437. doi:10.1016/j.msea.2004.08.062

[14] Taktak, S.: Mater. Design, 28, 2007, p. 1836. doi:10.1016/j.matdes.2006.04.017

[15] Gunes, I., Ulker, S., Taktak, S.: Mater. Design, 32, 2011, p. 2380. doi:10.1016/j.matdes.2010.11.031 
[16] Kobayashi, S., Yakou, T.: Mat. Sci. Eng. A-Struct., 338, 2002, p. 44. doi:10.1016/S0921-5093(02)00053-9

[17] Bates, B. L., Wang, Y. Q., Zhang, Y., Pint, B. A.: Surf. Coat. Tech., 204, 2009, p. 766 doi:10.1016/j.surfcoat.2009.09.063

[18] Tong, L., Dengzun, Y., Chungen, Z.: Chinese J. Aeronaut., 23, 2010, p. 381. doi:10.1016/S1000-9361(09)60231-4

[19] Zarchi, H. R. K., Soltanieh, M., Aboutalebi, M. R., Guo, X.: T. Nonferr. Metal. Soc, 24, 2014, p. 1959. doi:10.1016/S1003-6326(14)63277-5

[20] Kartal, G., Eryilmaz, O. L., Krumdick, G., Erdemir, A., Timur, S.: Appl. Surf. Sci., 257, 2011, p. 6928. doi:10.1016/i.apsusc.2011.03.034

[21] Campos-Silva, I., Ortiz-Dominguez, M., Bravo-Barcenas, O., Donu-Ruiz, M. A., Bravo-Barcenas, D., Tapia-Quintero, C., Jimenez-Reyes, M. Y.: Surf. Coat. Tech., 205, 2010, p. 403. doi:10.1016/i.surfcoat.2010.06.068

[22] Zhan, Z. L., He, Y. D., Wang, D. R., Gao, W.: Intermetallics, 14, 2006, p. 75 . doi:10.1016/i.intermet.2005.04.019

[23] Rashidi, A. M., Amadeh, A.: Intermetallics, 18, 2010, p. 1517. doi:10.1016/i.intermet.2010.04.005

[24] Juijerm, P., Altenberger, I.: Scripta Mater., 55, 2006, p. 1111. doi:10.1016/j.scriptamat.2006.08.047
[25] Nikitin, I., Altenberger, I.: Mat. Sci. Eng. A-Struct., 465, 2007, p. 176. doi:10.1016/i.msea.2007.02.004

[26] Balusamy, T., Narayanan, T. S. N. S., Ravichandran, K., Park, I. S., Lee, M. H.: Surf. Coat. Tech., 232, 2013, p. 60. doi:10.1016/j.surfcoat.2013.04.053

[27] Laleh, M., Kargar, F., Velashjerdi, M.: J. Mater. Eng. Perform., 22, 2013, p. 1304. doi:10.1007/s11665-012-0417-7

[28] Balusamy, T., Narayanan, T. S. N. S., Ravichandran, K., Park, I. S., Lee, M. H.: Vacuum, 97, 2013, p. 36. doi:10.1016/i.vacuum.2013.04.006

[29] Ren, X. D., Zhan, Q. B., Yuan, S. Q., Zhou, J. Z., Wang, Y., Ren, N. F., Sun, G. F., Zheng, L. M., Dai, F. Z., Yang, H. M., Dai, W. J.: Mater. Design, 54, 2014, p. 708. doi:10.1016/j.matdes.2013.08.054

[30] Feng, B. X., Mao, X. N., Yang, G. J., Yu, L. L., Wu, X. D.: Mat. Sci. Eng. A-Struct., 512, 2009, p. 105. doi:10.1016/i.msea.2009.01.028

[31] Xie, L. C., Jiang, C. H., Ji, V.: Mat. Sci. Eng. A-Struct., 528, 2011, p. 6478. doi:10.1016/i.msea.2011.04.075

[32] Nikitin, I., Besel, M.: Scripta Mater., 58, 2008, p. 239. doi:10.1016/i.scriptamat.2007.09.045 